\title{
Uniportal video-assisted thoracoscopic surgery pericardial window
}

\author{
Gaetano Rocco, MD, FRCS (Ed), antonello La Rocca, MD, a Carmine La Manna, MD, ${ }^{\text {a }}$ \\ Francesco Scognamiglio, MD, ${ }^{a}$ Massimiliano D'Aiuto, MD, ${ }^{a}$ Raj Jutley, MD, FRCS, \\ and Nicola Martucci, MD, ${ }^{a}$ Naples, Italy, and Sheffield, United Kingdom
}

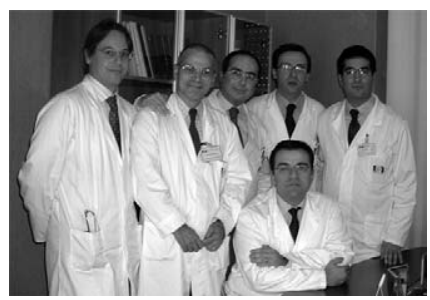

\section{See related article on page 919 .}

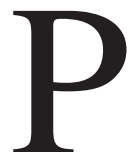

ericardial effusions often complicate the course of endstage malignant conditions. ${ }^{1}$ When frequent pericardiocentheses are required, a pericardial window is indicated to permanently relieve tamponade symptoms. In patients with acceptable performance status, such a procedure has been performed either through an open or a video-assisted thoracoscopic surgery (VATS) approach with excellent results. ${ }^{1}$

Between January 2002 and September 2005, 4 patients (2 women and 2 men; median age 46 years) with malignant pleuropericardial effusions ( 2 from breast cancer and 2 from lymphoma) had uniportal VATS pericardial window. In 1 patient with lymphoma, the same VATS approach also served to sample a mediastinal adenopathy in the anterior mediastinum. All patients were discharged home or transferred to a chemotherapy unit the day after surgery. No recurrence of pericardial effusion was observed at a median follow-up of 7 months.

The geometric rationale for uniportal VATS has been described. ${ }^{2,3}$ In brief, under general anesthesia, via single lung ventilation, and with the patient in the supine position or with the desired hemithorax elevated $\left(45^{\circ}\right)$ by an axillary roll, a single $2.5-\mathrm{cm}$ incision is placed in the fifth interspace along the axillary line. A 2.7- or 5-mm videothoracoscope is inserted and the pleural

From the Division of Thoracic Surgery, ${ }^{\text {a }}$ National Cancer Institute, Pascale Foundation, Naples, Italy, and The Price Thomas Thoracic Unit, ${ }^{\mathrm{b}}$ Northern General Hospital, Sheffield Teaching Hospitals, Sheffield, United Kingdom.

Received for publication Nov 3, 20045; revisions received Nov 30, 2005; accepted for publication Dec 9, 2005.

Address for reprints: Gaetano Rocco, MD, FRCS (Ed), FECTS, Division of Thoracic Surgery, National Cancer Institute, Pascale Foundation, Via M Semmola, 81 80131, Naples, Italy (E-mail: Gaetano.Rocco@btopenworld.com).

J Thorac Cardiovasc Surg 2006;131:921-2

$0022-5223 / \$ 32.00$

Copyright (C) 2006 by The American Association for Thoracic Surgery

doi:10.1016/j.jtcvs.2005.12.014 cavity inspected. A target area anterior to the phrenic nerve is selected, and a limited amount of fluid is evacuated though a pericardiocenthesis. ${ }^{1}$ The parietal pericardium is lifted cranially with thin forceps and opened with endoscissors inserted parallel to the thoracoscope (Figure 1,a-c). The window is completed by circumferential incisions of the pericardium (Figure 2, $a$ and $b$ ). A chest tube inserted through the same incision is left at the end of the procedure (Figure 2, c).

Uniportal VATS has demonstrated a significant versatility in the diagnosis and treatment of a variety of intrathoracic conditions. ${ }^{2,3}$ In addition, postoperative pain and residual paresthesias tend to be reduced after single port VATS compared with the traditional VATS approach. ${ }^{4}$ In patients with malignant pericardial effusions, one of the advantages of uniportal VATS is the utilization of the same incision often already created to insert a chest tube for a concurrent pleural effusion with minimal patient discomfort. In addition, a mediastinal nodal biopsy and talc pleurodesis can be carried out at the same time. On the other hand, uniportal VATS can be easily converted to the traditional 3-port approach or to minithoracotomy, thereby providing a backup option for surgeons in the learning curve. With the more extensive utilization of VATS procedures under locoregional anesthesia in the awake patient, we are currently investigating the potential for uniportal VATS pericardial windows to be performed in an outpatient or day-hospital setting. ${ }^{5}$

\section{References}

1. Georghiou GP, Stamler A, Sharoni E, Fichman-Horn S, Berman M, Vidne BA, et al. Video-assisted thoracoscopic pericardial window for diagnosis and management of pericardial effusions. Ann Thorac Surg. 2005;80:607-10.

2. Rocco G, Martin-Ucar A, Passera E. Uniportal VATS wedge pulmonary resections. Ann Thorac Surg. 2004;77:726-8.

3. Rocco G, Khalil M, Jutley R. Uniportal video-assisted thoracoscopic surgery wedge lung biopsy in the diagnosis of interstitial lung diseases. J Thorac Cardiovasc Surg. 2005;129:947-8.

4. Jutley RS, Khalil MW, Rocco G. Uniportal vs standard three-port VATS technique for spontaneous pneumothorax: comparison of postoperative pain and residual paraesthesia. Eur J Cardiothorac Surg. 2005;28:43-6

5. Pompeo E, Mineo D, Rogliani P, Sabato AF, Mineo TC. Feasibility and results of awake thoracoscopic resection of solitary pulmonary nodules. Ann Thorac Surg. 2004;78:1761-8. 


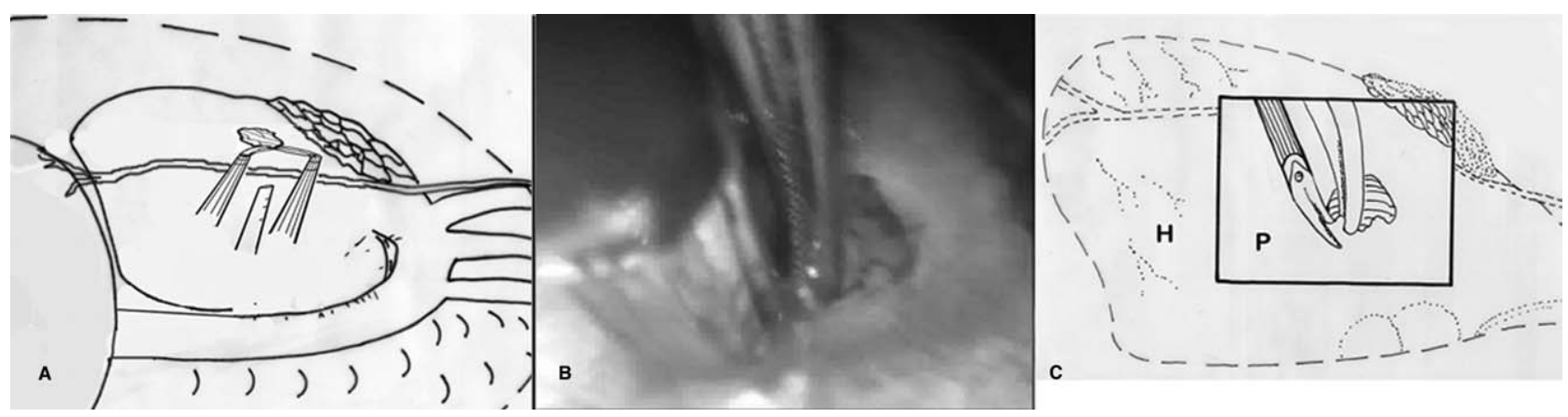

Figure 1. Schematic representation and intraoperative sequence of uniportal VATS pericardial window. a, Position of the thoracoscope and the instruments through the single incision. c, Technique of pericardial incision. $H$, Heart; $P$, pericardium.

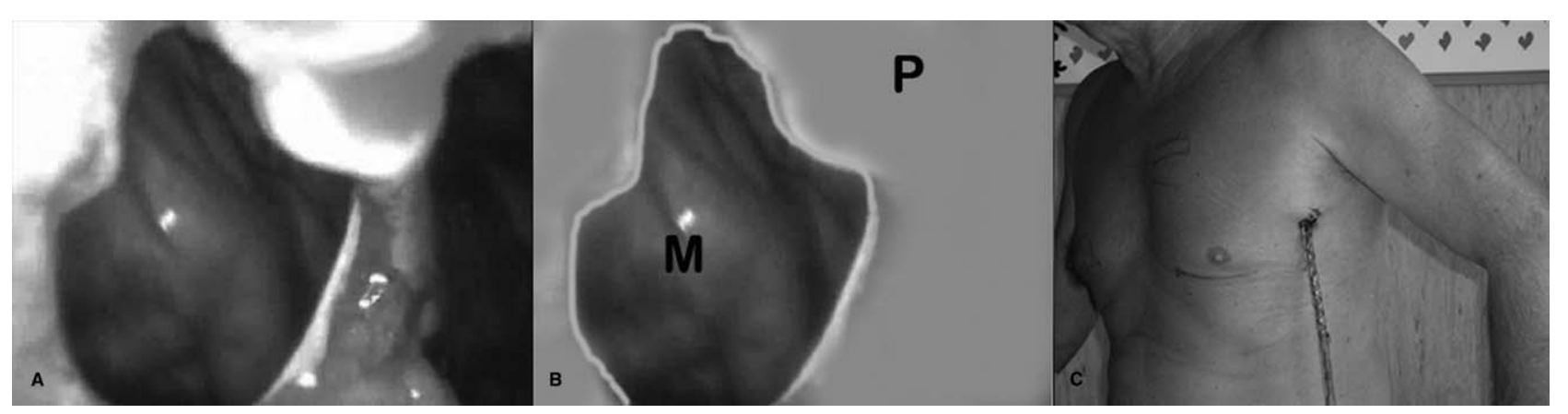

Figure 2. Final result of uniportal VATS pericardial window. a and b, Intraoperative view and schematic representation of the completed window. $P$, Pericardium; $M$, myocardium; c, Postoperative picture of the patient with the chest drain through the single port incision.

\section{Availability of Journal back issues}

As a service to our subscribers, copies of back issues of The Journal of Thoracic and Cardiovascular Surgery for the preceding 5 years are maintained and are available for purchase from Mosby until inventory is depleted. Please write to Mosby, Subscription Customer Service, 6277 Sea Harbor Dr, Orlando, FL 32877, or call $800-654-2452$ or $407-345-4000$ for information on availability of particular issues and prices. 